\title{
Practice
}

Teaching Case Report

\section{Superior vena cava syndrome and telangiectasia in a man}

\section{with lymphoma}

The case: A 30-year-old man presented with shortness of breath 5 days after returning from a Hawaiian vacation. He reported a 2-week history of progressive difficulty breathing and pain between his shoulder blades, especially when in a supine position. The patient had been previously well, and he was a nonsmoker. The patient described the difficulty breathing as being primarily the inability to take a deep breath. The pain was nonradiating, but it was felt centrally from front to back. He denied having any fever, nighttime sweats, weight loss, cough or exposure to any airborne fumigants. He reported that while on holiday he had been too tired to take part in a number of sporting activities in which he would have normally participated. The patient also reported having had a nonpruritic "rash" on his torso for about 1 week that had spontaneously resolved before he returned to Canada. On examination, the patient was not in distress, his vital signs were normal and he sat on the examination table in a somewhat flexed position. The patient's head and neck examination was unremarkable. Examination of his torso revealed a "band" of telangiectasia on the anterior portion of his lower chest (Figure 1). The patient reported that the band had appeared overnight, and that it was the same as the rash that had resolved 2 weeks earlier. The results of both cardiac (including electrocardiography) and respiratory examinations were unremarkable. In the supine position, the patient's respirations were exaggerated, and he noticeably used his chest and abdomen for inspiration. A radiograph showed a large anterior mediastinal mass and normal lungs and pleura (Figure 2). The results of a CT scan showed a heterogenous anterior mediastinal mass that measured $13 \times 9 \times 11 \mathrm{~cm}$ (lateral $\times$ anteroposterior $\times$ cranio-caudal) (Figure 3 ). The mass extended from the sternoclavicular joint to the margin of the anterior diaphragm. The mass abutted the right atrium and right ventricle, and it exerted substantial mass effect on the superior vena cava. The findings of immunohistochemical investigations were consistent with diffuse large B-cell lymphoma, a form of non-Hodgkin's lymphoma. The patient received 6 cycles of chemotherapy and 20 treatments of localized radiotherapy. Nine months after diagnosis, the patient remained cancer free.

Lymphomas are neoplastic transformations of cells that reside primarily in lymphatic tissue, including reticuloendothelial organs. Hodgkin's and nonHodgkin's lymphomas have differing cellular origins, presentations and clinical characteristics (Table I).

Our patient's lymphoma was diagnosed in part because he presented with acute superior vena cava syn- drome. This syndrome occurs when venous return from the upper half of the body is obstructed, which causes dyspnea that is often aggravated when the patient lies in a supine position. A patient with superior vena cava syndrome may experience respiratory problems and coughing, which are often exacerbated when the patient is supine because gravity engages the mass directly against the superior vena cava. Tracheobrochial compression could have also contributed to our patient's breathing difficulties. Although not experienced by our patient, other findings that are typical of superior vena cava syndrome include venous distension of the neck and chest wall, edema of the face and upper extremities, mental changes (altered mentation or level of consciousness), cyanosis and visual changes due to papilledema.

The differential diagnosis for a large anterior mediastinal mass includes the 5 Ts: thymoma, teratoma, thyroid cancer, thoracic aortic aneurysm and tumour. In theory, any of these conditions could cause superior vena cava syndrome; however, it is frequently caused by certain types of lymphoma. Our patient ultimately received a diagnosis of diffuse large B-cell lymphoma, a specific type of

Figure 1: Telangiectasia on the patient's anterior thorax. 


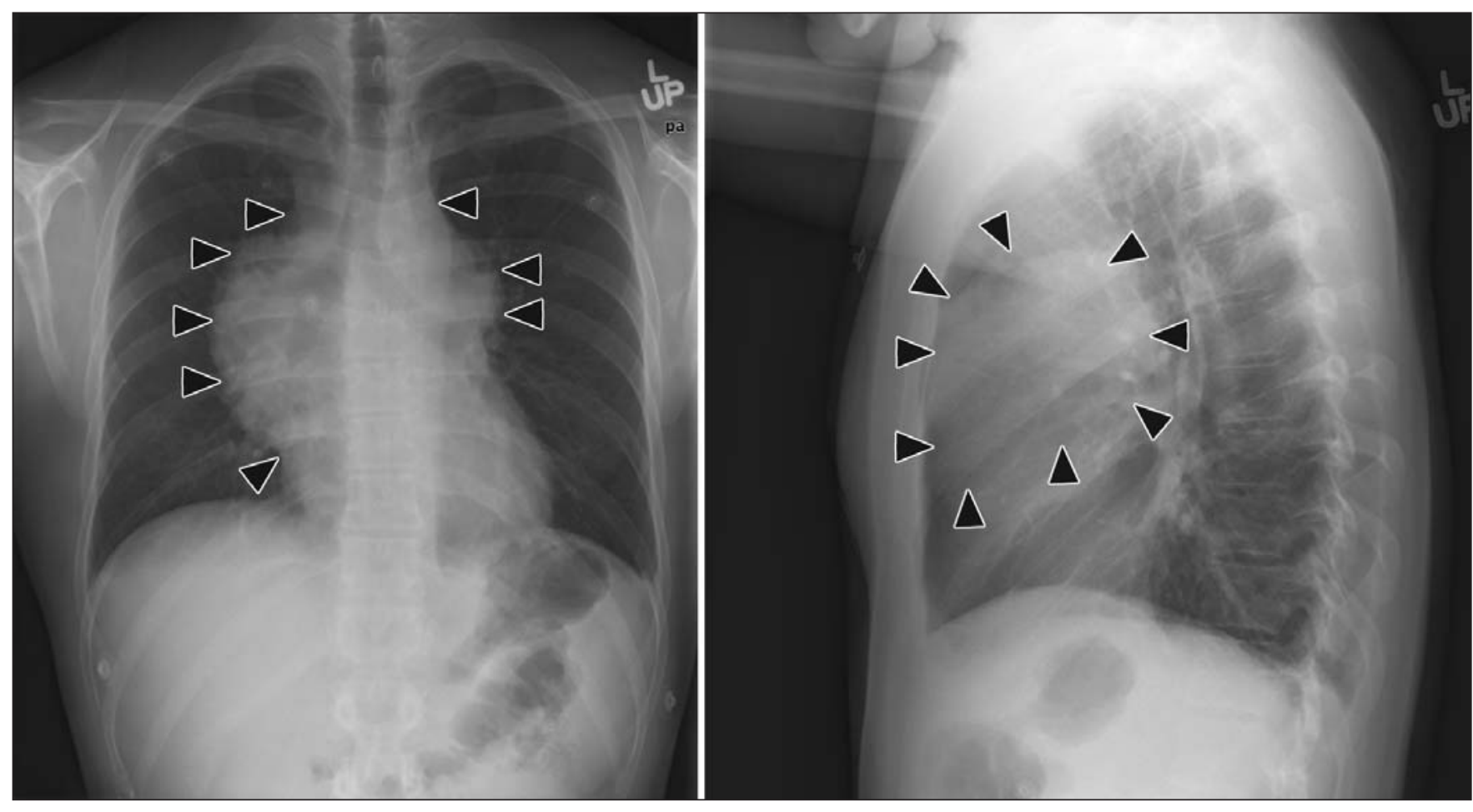

Figure 2: Chest radiographs showing a large anterior mediastinal mass (arrowheads). (Left) anteroposterior view. (Right) lateral view.

non-Hodgkin's lymphoma that commonly leads to superior vena cava compression. ${ }^{1}$ Although there are more than 20 types of non-Hodgkin's lymphoma, diffuse large B-cell lymphoma is by far the most common, making up about

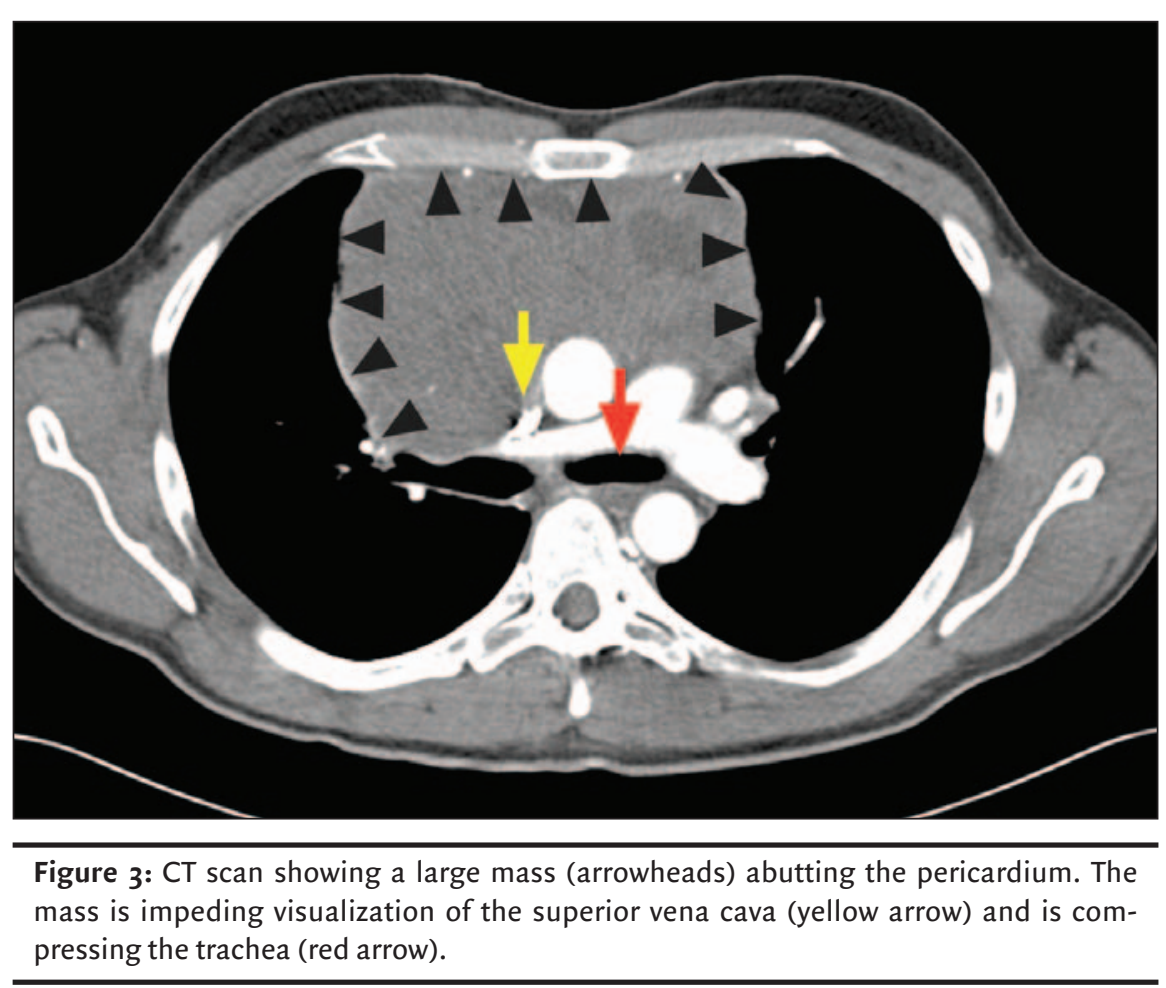

Figure 3: CT scan showing a large mass (arrowheads) abutting the pericardium. The mass is impeding visualization of the superior vena cava (yellow arrow) and is compressing the trachea (red arrow).

$30 \%$ of all lymphomas. ${ }^{2}$ Up to $80 \%$ of all primary mediastinal large B-cell lymphomas display evidence of superior vena cava compression. In direct contrast, despite the fact that mediastinal lymphadenopathy is a common feature of Hodgkin's disease, it rarely causes superior vena cava syndrome.

A telangiectasial rash is typically caused by either a primary cutaneous disorder or a systemic disease. Primary cutaneous disorders that cause telangiectasia include actinic dermal damage, venous hypertension, rosacea, poikilodermal disorders and essential telangiectasia. Systemic diseases causing telangiectasia includes autoimmune diseases (e.g., systemic lupus erythematosus, dermatomyositis, scleroderma), high-estrogen states (e.g, pregnancy, cirrhosis), genetic disorders (e.g, hereditary hemorrhagic telangiectasia, ataxia telangiectasia), malignant diseases (e.g., carcinomatosis, lymphoma) and conditions that cause venous obstruction (e.g., superior vena cava syndrome).

Although patches of telangiectasia are often a major manifestation of angiotropic (intravascular) lymphoma, a type of non-Hodgkin's lymphoma, our patient did not have this disease. Instead, marked dilation of veins or venules (often in vertical parallel clusters on the chest above the level of the heart) may be an early cutaneous finding of superior vena cava syndrome, as 
occurred in our patient. These dilated vessels are thought to be caused by increased collateral flow through the subcutaneous vessels of the chest wall. As in our case, the engorged vessels typi- cally shrink or disappear with relief of the obstruction of blood flow.

The presentation of lymphomas is notoriously variable. This case is notable because our patient denied having many

Table 1: Features of Hodgkin's and non-Hodgkin's lymphoma

\begin{tabular}{|c|c|c|}
\hline Characteristic & Hodgkin's lymphoma & Non-Hodgkin's lymphoma \\
\hline Sex & $\begin{array}{l}\text { Affects more men than } \\
\text { women }\end{array}$ & $\begin{array}{l}\text { Affects more men than } \\
\text { women }\end{array}$ \\
\hline Age, yr & $\begin{array}{l}\text { Greatest risk: } \\
15-35,>55\end{array}$ & Risk increases with age \\
\hline $\begin{array}{l}\text { Chromosomal } \\
\text { translocation }\end{array}$ & $B c l-2$ & No \\
\hline $\begin{array}{l}\text { Presence of "B" } \\
\text { symptoms* }\end{array}$ & $\begin{array}{l}58 \% \text { of cases (common at } \\
\text { presentation) }\end{array}$ & $\begin{array}{l}60 \% \text { of cases (common later } \\
\text { in disease course) }\end{array}$ \\
\hline Cutaneous involvement & No & Subtype dependent \\
\hline Thorax involvement & $85 \%$ of cases & $45 \%$ of cases \\
\hline Course & Indolent to aggressive & Indolent to aggressive \\
\hline Cellular pathology & Reed-Sternberg cells & Subtype dependent \\
\hline Mode of spread & Lymphatic & Contiguous, hematogenous \\
\hline Survival & $>85 \%$ & Subtype dependent \\
\hline
\end{tabular}

*Includes drenching nighttime sweats, > $10 \%$ weight loss in a 6 -month period, fever.

of the common "B" symptoms of lymphoma (Table I), yet he demonstrated signs of superior vena cava obstruction, which is common among patients with diffuse large B-cell lymphoma. This particular presentation is but one of the million faces of lymphoma.

\section{Tony F. Bruno MD MSc \\ Michel Donoff MD \\ Department of Family Medicine \\ University of Alberta \\ Edmonton, Alta.}

This article has been peer reviewed.

Competing interests: None declared.

\section{REFERENCES}

I. Jacobson JO, Aisenberg AC, Lamarre L, et al. Mediastinal large cell lymphoma. An uncommon subset of adult lymphoma curable with combined modality therapy. Cancer ig88;62:1893-8.

2. Armitage JO, Weisenburger DD. New approach to classifying non-Hodgkin's lymphomas: clinical features of the major histologic subtypes. NonHodgkin's Lymphoma Classification Project. J Clin Oncol I998; 6 : 2780-95.

\section{Canadian Adverse Reaction Newsletter Bulletin canadien des effets indésirables}

To receive the Newsletter and health product Advisories free by email, join Health Canada's MedEffect mailing list.

Go to www.healthcanada.gc.calmedeffect

Inscrivez-vous à la liste MedEffet de Santé Canada pour recevoir gratuitement par courriel le Bulletin et les Avis au sujet des produits de santé. Rendez-vous à l'adresse www.santecanada.gc.calmedeffet

Report adverse reactions toll free to Health Canada Signaler sans frais des effets indésirables à Santé Canada

Tel./Tél. : 866 234-2345 • Fax/Téléc. : 866 678-6789 